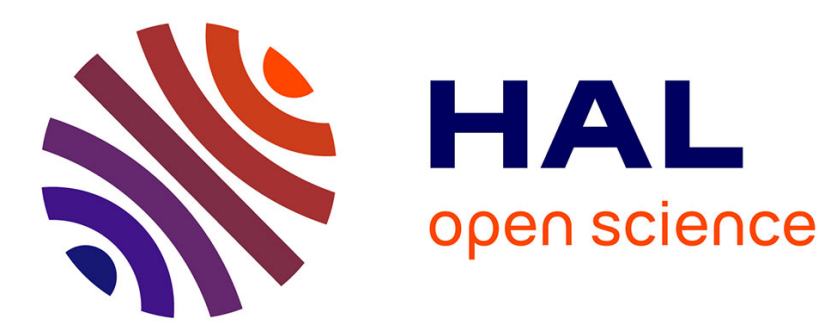

\title{
STRUCTURE OF SODIUM ALUMINOSILICATE GLASSES : T1 LUMINESCENCE SPECTROSCOPY
}

P. Onorato, Alexander M. Hoole, C. Struck, G. Tasker, D. Uhlmann

\section{To cite this version:}

P. Onorato, Alexander M. Hoole, C. Struck, G. Tasker, D. Uhlmann. STRUCTURE OF SODIUM ALUMINOSILICATE GLASSES: T1 LUMINESCENCE SPECTROSCOPY. Journal de Physique Colloques, 1985, 46 (C8), pp.C8-235-C8-240. 10.1051/jphyscol:1985834 . jpa-00225177

\section{HAL Id: jpa-00225177 https://hal.science/jpa-00225177}

Submitted on 1 Jan 1985

HAL is a multi-disciplinary open access archive for the deposit and dissemination of scientific research documents, whether they are published or not. The documents may come from teaching and research institutions in France or abroad, or from public or private research centers.
L'archive ouverte pluridisciplinaire HAL, est destinée au dépôt et à la diffusion de documents scientifiques de niveau recherche, publiés ou non, émanant des établissements d'enseignement et de recherche français ou étrangers, des laboratoires publics ou privés. 


\title{
STRUCTURE OF SODIUM ALUMINOSILICATE GLASSES : TI LUMINESCENCE SPECTROSCOPY
}

\author{
P.I.K. Onorato, M.N. Alexander, C.W. Struck, G.W. Tasker and D.R. Uhlmann \\ G.T.E. Laboratories, Ine., Waltham, Mass., U.S.A. \\ * Massachusetts Institute of Technology, Cambridge, Mass., U.S.A.
}

\begin{abstract}
Résumé - Les spectres optiques des ions $\mathrm{T}^{+}{ }^{+}$, correspondant à une émission à

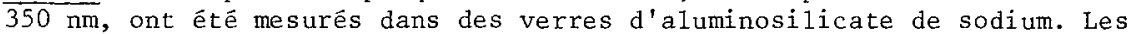
spectres mettent en évidence deux contributions dues respectivement à $\mathrm{T}^{+} \mathrm{agis}^{-}$ sant comme modifieur du réseau ou comme compensateur de charge pour l'aluminium. Quand le rapport Al/Na devient plus grand que 1 , le spectre de compensation de charge est seul observé. En dessous de 1, le spectre de modifieur du réseau prend de plus en plus d'importance quand $\mathrm{Al} / \mathrm{Na}$ décrốt. Ceci est bien en accord avec le modèle traditionnel des structures d'aluminosilicate alcalins, où la composition critique pour la disparition des oxygènes non-pontants est donnée par $\mathrm{A} 1 / \mathrm{Na}=1$.
\end{abstract}

Abstract - Optical excitation spectra of $\mathrm{Tl}^{+}$ions, corresponding to emission at $\overline{350 \mathrm{~nm}}$, have been measured in $\mathrm{Na}$ aluminosilicate glasses. The excitation spectra are shown to be superpositions of two primary spectra, which are identified with $\mathrm{Tl}^{+}$acting as network modifiers or as charge compensators for network aluminums. When $\mathrm{Al} / \mathrm{Na} \geq \mathrm{I}$, only the charge compensator spectrum can be observed. As Al/Na decreases below unity, the fraction of the charge compensator spectrum decreases rapidly, and the fraction of the network nodifier spectrum increases correspondingly. These results strongly support the traditional model of alkali aluminosilicate structure, in which the critical compositions for (dis)appearance of nonbridging oxygens are given by $\mathrm{Al} / \mathrm{Na}=1$; they contradict reports of XPS measurements from which it had been concluded that the critical compositions are given by $\mathrm{Al} / \mathrm{Na} \simeq 0.7$. The network modifier spectra do not depend strongly on glass composition, whereas the charge compensator peaks vary significantly with composition. 'These results are fully consistant with new oxygen ls XPS spectra.

\section{I - INTRODUCTION}

It has been generally accepted that addition of an alkali oxide to $\mathrm{SiO}_{2}$ breaks up the $\mathrm{Si-O}-\mathrm{Si}$ network and creates nonbridging oxygens (NBO's). Introduction of $\mathrm{Al}_{2} \mathrm{O}_{3}$ into an alkali silicate glass, conversely, is believed to eliminate NBO's and simultaneously create bridging oxygens ( $\mathrm{BO}^{\prime} \mathrm{s}$ ). Aluminum ions are thought to occupy fourcoordinated network positions, requiring alkali ions as charge compensators (CC's). In this traditional model, $\mathrm{NBO}^{\prime} \mathrm{s}$ and $\mathrm{BO}^{\prime} \mathrm{s}$ are both present when the alakli concentration exceeds the aluminum concentration ( $\mathrm{Al} / \mathrm{R}<1$ ). A large body of experimental 
results has been interpreted in terms of this model $/ 1-9 /$.

This consensus was recently challenged by X-ray photoelectron spectroscopy (XPS) studies by Brückner et a1 $/ 10,11 /$ and by Smets and Lommen $/ 12 /$. These authors found a partially resolved splitting between XPS oxygen 1 s lines and ascribed the splitting to the difference in binding energies of BO and NBO. They found the NBO XPS line disappeared when AI/R $\geq 0.67$ in Na aluminosilicate glasses, and they argued that six-coordinated aluminum must therefore be present when $A 1 / R<1$, and that sixcoordinated aluminum, by "consuming" NBO's, causes the fraction of NBO's to become zero at $A I / R \simeq 0.67$.

The articles by Brückner et al and Smets and Lommen have inspired the optical studies reported here and, in addition, XPS research that is reported in detail in another paper at this conference $/ 13 \%$. In the optical investigations, luminescence of $\mathrm{T}^{+}$ is measured and analyzed in order to understand $\mathrm{Na}^{+}$environments in $\mathrm{Na}$ aluminosilicate glasses. It is assumed that $\mathrm{TI}^{+}$acts, to a good approximation, as an optically active iva ${ }^{+}$ion, so that optical spectroscopy of $\mathrm{Tl}^{+}$ions probes the environments of $\mathrm{Na}^{+}$ions.

\section{EXPERIMENTAL}

Glass samples were prepared from batches consisting of $99.999 \%$ pure $\mathrm{iaa}_{2} \mathrm{CO}_{3}, \mathrm{NaAlO}_{2}$, $\mathrm{SiO}_{2}$, and $\mathrm{Al}_{2} \mathrm{O}_{3}$. Thallium was added as $\mathrm{TlNO}_{3}$. Samples were melted in a platinumcovered platinum crucible for 5-30 hours at 1500-1630 C, transferred to a furnace at $1100 \mathrm{C}$, and cooled slowly to room temperature. Samples containing high concentrations of $\mathrm{Na}_{2} \mathrm{O}$ were stored in a drybox and cut and polished in kerosene. Glasses were cut and polished to make slices $1.0 \mathrm{Inm}$ thick.

Some compositions were chosen to have constant theoretical optical basicity, $\Lambda_{\mathrm{TH}}=$ 0.57 , in order to separate effects due to $\mathrm{NBO}$ concentration on the $\mathrm{TI}^{+}$spectra from the effects of average host glass composition. The theoretical optical basicity, which may be calculated from glass composition, is designed to characterize the electron donating ability of the glass. One reason that this characterization, is only partially successful is that the introduction of $1 \mathrm{BO}^{\prime} \mathrm{s}$ causes variations in the local electron donating ability of the glass /15/. Additional compositions were cnosen to have theoretical basicities, $\Lambda_{\mathrm{TH}}$, of 0.55 and 0.60 witi a theoretical fraction of NBO's, $f_{\mathrm{NBO}}$, of 0.0 and 0.134 . Figure 1 shows the compositions of the glasses used in this study and those used by Brückner et a1 $/ 10,11 \%$. Note that the composition lines for our samples and those of Brückner et al intersect near the composition at which Brückner et al suggest the disappearance of $\mathrm{NBO}^{\prime} \mathrm{s}$.

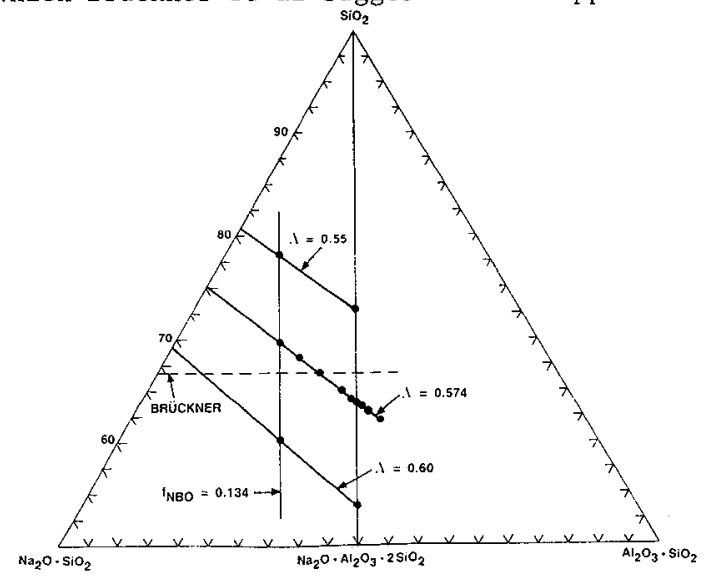

FIGURE 1 - Elemental compositions of glasses used in this work (dark circles). The composition join for glasses used in XPS studies by Erückner et al $/ 10,11 /$, is indicated by the broken line. 
Thallium concentrations were 0.001 to $0.005 \mathrm{M}$. Samples at the higner concentration exhibited a small amount of line broadening, which is likely due to Tl-Tl coupling. Clustering has been observed at considerably higher Tl concentrations $(\geq 0.1 \mathrm{M}$ in $\mathrm{T} 1$ silicate glasses) than we employed /16-13/. Line broadening at $0.00 \overline{5} \mathrm{M} 1 \mathrm{~T}$ quite surprising.

Optical spectra were measured at room temperature on a spex Fluorolog Hodel 1902 spectrofluorometer whose output was fed, via an IBH 7406 Device Coupler, to the GTE Laboratories mainframe computer. All spectra were corrected for instrumental effects through calibrations stored in the computer.

\section{Results}

An adequate reproduction of the absorption spectrum was obtained by recording the intensity of $\mathrm{TI}^{+}$emission at $350 \mathrm{~nm}$ as a function of excitation wavelength (excitation spectrum). $350 \mathrm{~nm}$ is on the long-wavelength side of the Tl+ emission maximum for all the spectra. While it is not true in general that excitation spectra faithfully reproduce absorption spectra, it appears that $\mathrm{Tl}^{+}$excitation spectra in sodium aluminosilicate glasses do reproduce the absorption spectra when the emission wavelength detected is greater than the wavelength of the emission peak. Good signal-to-noise ratios could, without much difficulty, be obtained for the $\mathrm{Tl}^{+}$excitation spectra. Therefore, excitation spectra at $350 \mathrm{~nm}$ have been used in place of absorption spectra in this research.

Figuxe 2 exhibits excitation spectra for glasses having Al/Na ratios of $0.42,0.55$, $0.69,0.85$, and 1.00 . By comparing the spectra of the glasses to published free-ion $\mathrm{Tl}^{+}$spectra and to spectra of $\mathrm{Tl}^{+}$in alkali halides, we assign the low-energy peaks of the $\mathrm{Al} / \mathrm{Na}=0.42,0.55,0.69$, and 0.85 spectra in Figure 2 to ${ }^{1} \mathrm{~S}_{\mathrm{o}} \rightarrow{ }^{3} \mathrm{P}_{1}$ transitions, and the high energy peaks to $i_{\mathrm{S}_{\mathrm{O}}} \rightarrow{ }^{3} \mathrm{P}_{2}$ transitions. According to this assignment, the single ${ }_{3}$ peak of the $\mathrm{Al} / \mathrm{Na}=1.00$ spectrum in $\mathrm{Fig}$. 2 is a ${ }^{1} \mathrm{~S}_{\mathrm{O}} \rightarrow{ }^{3} \mathrm{P}_{1}$ transition; the ${ }^{1} \mathrm{~S}_{\mathrm{o}} \rightarrow{ }^{3} \mathrm{P}_{2}$ peak is presumed to lie below $200 \mathrm{~nm}$.

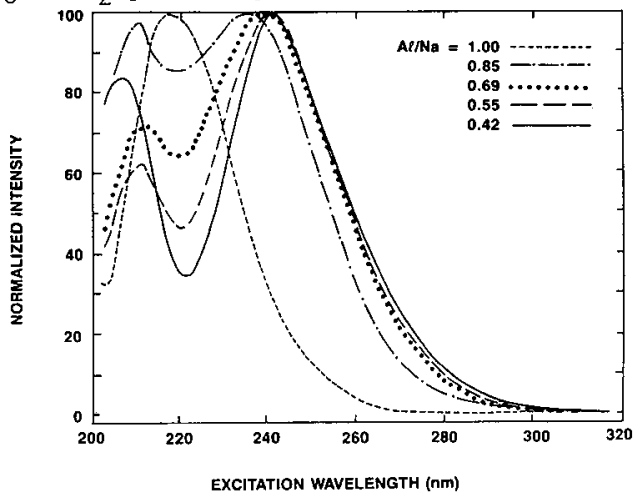

FIGURE $2-\mathrm{Tl}^{+}$excitation spectra (emission at $350 \mathrm{~nm}$ detected) of Na aluminosilicate glasses having various Al/ $\mathrm{Na}$ molar ratios. $\Lambda_{\mathrm{TH}}=0.574$

The excitation spectra shown in Fig. 2 apparently arise from two different kinds of primary spectra. The Type I excitation spectrum peaks near $220 \mathrm{~nm}$ (heavy dashed spectrum in Fig. 2), and is characteristic of glasses for which Al/Na $\geq 1$. The Type II excitation spectrum is characterized by peaks near 210 and $240 \mathrm{~nm}$. As can be seen from Fig. 2, the intensity of the Type I spectrum decreases--while the intensity of the Type II spectrum increases--as $\mathrm{Al} / \mathrm{Na}$ decreases (when $\mathrm{Al} / \mathrm{Na}<1$ ).

The transition from Type I to Type II spectra proceeds rapidly as a function of Al/Na. The solid line in Fig. 3 is the excitation spectrum for samples with $\mathrm{Al} / \mathrm{Na} \geq 1$. The dashed line is for glasses with $\mathrm{Al} / \mathrm{Na}=0.96$. According to the traditional model of aluminosilicate glass structure, only $0.7 \%$ of the oxygen atoms in an $\mathrm{Al} / \mathrm{Na}=0.96$ glass are $\mathrm{NBO}^{\prime} \mathrm{s}\left(\mathrm{f}_{\mathrm{NR} n}=0.007\right)$. Thus, a small change in com- 


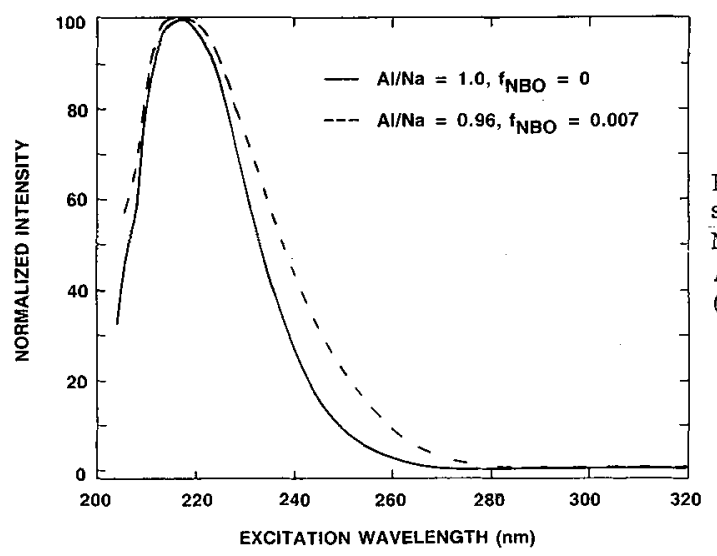

FIGURE 3 - Comparison of $\mathrm{TI}^{+}$excitation spectra (emission at $350 \mathrm{~nm}$ detected) of Na aluminosilicate glasses having $\mathrm{A} 1 / \mathrm{Na}>1$ (solid line) and $\mathrm{Al} / \mathrm{Na}=0.96$ (dashed line). $\Lambda_{\mathrm{TH}}=0.574$.

position results in a large change in the spectrum. One can see from Fig. 2 that little of the Type I spectrum remains when $\mathrm{Al} / \mathrm{Na}=0.42$, a composition at which, according to the traditional model, $\mathrm{f}_{\mathrm{NBO}}=0.134$.

\section{DISCUSSION}

The most straightforward interpretation of the $\mathrm{Tl}^{+}$excitation spectra in $\mathrm{Na}$ aluminosilicate glasses is that they are superpositions of primary spectra due to $\mathrm{TI}^{+}$acting as CC (Type I spectra) and $\mathrm{N1}^{+}$acting as network modifiers (Type II spectra). This assignment accords with the fact that the relative intensity of the network modifier (NKI) spectrum increases as the glass becomes increasingly Na-rich. Moreover, the spectra cease to change when $\mathrm{Al} / \mathrm{Na} \geqslant 1$; such a break-point is consistent with the traditional model of aluminosilicate glass structure. In fact, spectra of glasses with $0.42<\mathrm{Al} / \mathrm{Na}<1.0$ can be synthesized from the end member spectra. The superpositions reprouice the important features of the experimental spectra very well, as seen in Figure 4. There is a preference Eor $\mathrm{Tl}^{+}$in $\mathrm{NM}$ sites, and this is consistent for all values of $\mathrm{Al} / \mathrm{Na}<1$.

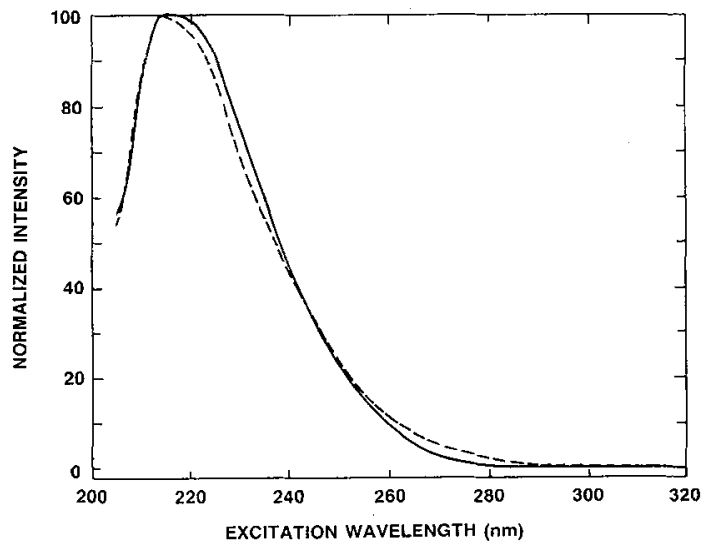

FIGURE $4-\mathrm{Tl}^{+}$excitation spectrum of $\mathrm{A} 1 / \mathrm{Na}=0.96 \mathrm{Na}$ aluminosilicate glass (solid line) and "best fit" (dashed line) obtained by superposing $80 \%$ Type I (CC) and $20 \%$ Type II (NM) spectra.

Two more considerations argue in favor of CC and NM assignments for the primary spectra. First, the assignment of the lower energy bands to $\mathrm{T}^{+}(\mathrm{NM})$ ions is reasonable because such ions may readily establish bonds that are more covalent than bonds formed by $\mathrm{Tl}^{+}$(CC) ions. The additional "electron sharino possible for $\mathrm{T1}^{+}(\mathrm{IM})$ 's can result in enhanced screening of the positive nucleus, and, can lower optical transition energies. It therefore is plausible that the optical transitions of $\mathrm{Tl}^{+}(\mathrm{NM})$ ions occur at lower energies than the transitions of $\mathrm{Tl}^{+}$(CC) ions. 
Second, this assignment of bands is supported indirectly by XPS results of Veal et al, who found that the charge residing on NBO's in Na silicate glasses changes little as a function of $\mathrm{Si} / \mathrm{Na} / 19 /$. We have obtained similar results in more detailed XPS studies of Na silicates and aluminosilicates /13/. The XPS data imply that only minor changes occur in the chemical environment of NM thalliums as a function of composition.

Additional information about the nature of $N M$ and $C C$ environments that agrees with XPS results was gained by varying the theoretical optical basicity for $\mathrm{f}_{\mathrm{NBO}}=0.0$ and 0.134. The composition dependence of the spectra of glasses with $f_{N B O}=0.0$ is shown in Fig. 5. These glasses have excitation spectra from $\mathrm{Tl}^{+}$in CC environments and peaks that shift to lower energies with increasing $\Lambda_{\mathrm{TH}}$. In contrast, the (predominantly) NM TI ${ }^{+}$spectra of glasses with $f_{\mathrm{NBO}}=0.134$ exhibit a much smaller dependence on composition (Fig. 6).

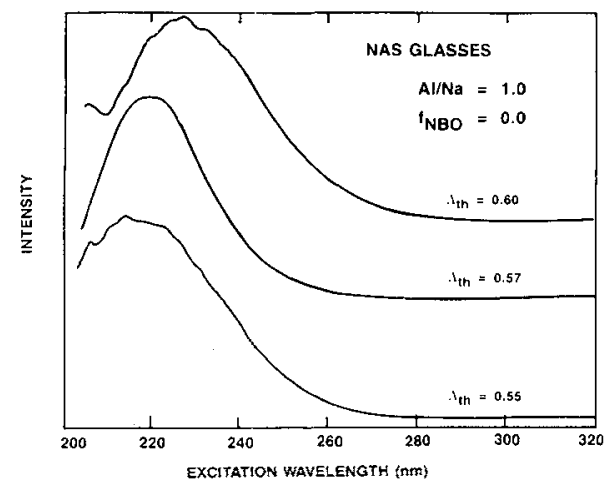

FIGURE 5 - Composition dependence excitation peak of $\mathrm{TI}^{+}$in $\mathrm{CC}$ sites.

When the experimental optical basicity $\left(\Lambda_{\text {exp }}\right)$ is calculated from the peak of the excitation spectra, the optical behavior of the $\mathrm{Tl}^{+}$-doped glasses can be interpreted in the light of optical basicity theory (Fig. 7). CC excitation bands agree semiquantitatively with $\Lambda_{\mathrm{TH}}$, although the actual composition dependence is greater. However, IM excitation bands indicate an environment that is significantly more basic than that predicted by the "average" basicity, indicative of an environment dominated by nearby NBO's. The weak composition dependence of the NM spectra indicates that the electron density on NBO's changes little with composition in Na aluminosilicate glasses, whereas the electron density on bridging oxygens (BO's) depends strongly upon composition.

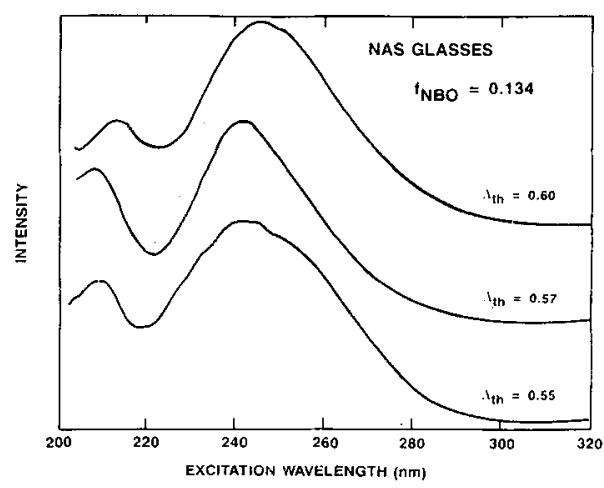

FIGURE 6 - Composition dependence of excitation peak of $\mathrm{TI}^{+}$in $\mathrm{NM}$ sites

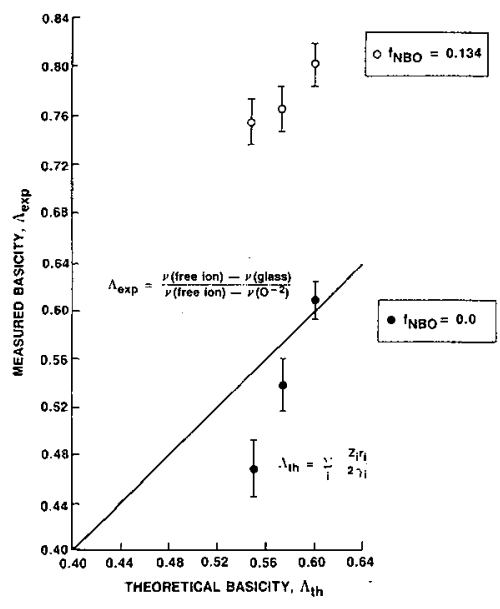

FIGURE 7 - Measured vs. theoretica1 optical basicity /14/ of NAS glasses. 
The composition dependence of $\mathrm{NM}$ and $\mathrm{CC} \mathrm{T1}{ }^{+}$ions is attributed to differences in local environments due to different numbers of nearby $\mathrm{Si}$ and Al cations. Oxygen bonded to Si would carry a different amount of electron charge than oxygens bonded to Al. This would result in $\mathrm{Tl}^{+}$luminescence being a function of the next-nearestneighbors, an analog of the fact that the XPS binding energy depends on whether the $\mathrm{BO}$ occurs in an Si-O-Si or in an Si-0-Al network configuration. The low energy (high measured basicity) of the NM peak reflects the high electron density of NBO's and agrees with the low oxygen ls binding energy from the XPS results.

\section{SUMMARY}

Excitation spectroscopy of $\mathrm{TI}^{+}$doped Na aluminosilicate glasses has shown that $\mathrm{TI}^{+}{ }^{+}$ present in two types of sites: network modifier sites associated with NBO's and charge compensator sites associated with network Al. There is no change in $\mathrm{Tl}^{+}$ spectra for glasses with $\mathrm{Al} / \mathrm{Na} \geq 1.0$ and there is a rapid appearance of the NM peak for glasses with $\mathrm{Al} / \mathrm{Na}<1.0$. $\overline{\mathrm{T}}^{+}$spectra for glasses with $0.42 \leq \mathrm{A} 1 / \mathrm{Na}<1.0$ can be fitted to a linear combination of $\mathrm{CC}$ and NM peaks. The results lead to the conclusion that $\mathrm{NBO}^{\prime} \mathrm{s}$ are present in all $\mathrm{Na}$ aluminosilicate glasses for which $\mathrm{Al} / \mathrm{Na}<1.0$.

Furthermore, the energy of $\mathrm{CC}$ peaks is a strong function of glass composition, reflecting the difference between electron densities of oxygens in Al-O-Si and Si-O-Si configurations. The energy of NM peaks is a weak function of composition and is influenced primarily by associated NBO's and only secondarily by other coordinating oxygens. The low energy of the $\mathrm{T}^{+}$excitation peak reflects the high electron density of NBO's.

Luminescence and XPS results produce a unified view of Na aluminosilicate glasses. The $\mathrm{TI}^{+}(\mathrm{CC})$ and $\mathrm{TI}^{+}(\mathrm{NM})$ peaks are counterparts of the XPS "BO peaks" and NBO peaks. Trends in the positions of the $\mathrm{Tl}^{+}$peaks as a function of glass composition can be understood from trends in the XPS data; conversely, many features of the XPS can be understood from the Iuminescence results.

\section{REFERENCES}

/1/ D.E. Day and G.E. Rindone, J. Am. Ceram. Soc. 45 (1962) 489, 496, 579.

/2/ J.0. Isard, J. Soc. Glass Tech. 43 (1959) 113.

/3/ E.R. Riebling, J. Chem. Phys. 44 (1966) 2857.

14/ T. Hanada, T. Aikawa, and N. Soga, J. Non-Cryst. Solids, 50 (1982) 397.

15/ G.W. Schulz, W. Müller-Warmuth, W. Poch, and G. Scherxer, Glastechn. Ber. 41 (1968) 435.

16/ J.E. Shelby and R.J. Eagan, J. Am. Ceram. Soc., 59 (1976) 420.

17/ J.E. Shelby, J. Appl. Phys. 49 (1978) 5885.

$/ 8 / \mathrm{K}$. Hunhold and R. Brückner, Glastechn. Ber. 53 (1980) 149.

/9/ T.D. Taylor and G.E. Rindone, J. Am. Ceram. Soc. 53 (1970) 692.

/10/ R. Briickner, H.-U. Chun, and H. Goretzki, Glastechn. Ber. 51 (1978) 1.

/11/ R. Brïckner, H.-U. Chun, H. Goretzki, and M. Sammet, J. Non-Cryst. Solids, 31 (1980) 49 .

$112 /$ B.M.J. Smets and T.P.A. Lommen, Phys. Chem. Glasses 22 (1981) 158.

/13/ G.W. Tasker, D.R. Uhlmann, P.I.K. Onorato, M.N. Alexander, C.W. Struck, this issue, paper A40.

/14/ J.A. Duffy and M.D. Ingram, J. Non-Cryst. Solids 21 (1976) 373.

/15/.R.K. Klein and P.I.K. Onorato, Phys. Chem. Glasses 21 (1980) 199.

/16/ L.W. Panek and P.J. Bray, J. Chem. Phys. 66 (1977) 3822.

/17/ M.E. Milberg and C.R. Peters, Phys. Chem. Glasses 10 (1969) 46.

/18/ W. Müller-Warmuth and H. Eckert, Phys. Lett. C (Phys. Rept.) 88 (1982) 91.

/19/ B.W. Vea1, D.J. Lam, A.P. Paulikas, and W.V. Ching, J. iNon-Cryst. Solids 49 (1982) 309. 